\title{
Fluctuation of Plasma Cortisol Levels in Multiple Sclerosis
}

\author{
F. M. Butterworth, G. E. Ristow, E. Collarini
}

SUMMARY: Using radioimmunoassay, the levels of plasma cortisol of 23 patients with multiple sclerosis and 10 control subjects were determined at three or more times over a one-year period. The status of the disease w'as ascertained b!' neurological examination at the same time. Tw'elve of the patients were considered stable because they showed no changes in their disease status during the year. The remaining 11 patients were designated active since each had one or more relapses. The levels of

RÉSUMÉ: Nous avons déterminé, par radioimmunoessai, les taux de cortisol plasmatique chez 23 patients atteints de sclérose en plaques et 10 sujets contrôles, et ce trois fois ou plus au cours d'une année. L'état de la maladie fut simultanément évalué par examen neurologique. Douze de ces patients furent considérés stables, n'ayant subi aucune modification de leur état au cours de l'année. Les onze autres furent considérés comme actifs, car ils eurent un ou plusieurs épisodes au cours de cortisol of the control and stable groups remained relatively constant during the one-year period, but the levels of the active group fluctuated significantly more than either of the other two groups. Furthermore the active patients who had more than one episode had the greatest fluctuation in their cortisol levels. The fluctuations could indicate some endocrinological aberration in patients with active multiple sclerosis or may be secondary to the influence of the disease.

l'année. Le taux de cortisol demeura relativement constant durant l'année chez les deux groupes étudiés, mais les niveaux fluctuaient significativement plus dans le groupe actif. Les patients actifs ayant subi plus d'une rechute avaient le plus de fluctuations dans leur niveau de cortisol. Ces variations pourraient tradiure une anomalie endocrinienne chez les patients sclérosés en phase active, mais elles pourraient aussi être secondaires au processus morbide lui-même.
From the Department of Biological Sciences, Oakland University, Rochester, Michigan and the Department of Neurology, Wayne State University.

Reprint requests to: Dr. F. M. Butterworth, Dept. of Biological Sciences, Rochester Michigan 48063 U.S.A.

\section{INTRODUCTION}

The cause of multiple sclerosis (MS) is unknown, but the immune system is clearly involved. For example, a significant number of MS patients have subpopulations of abnormal $\mathrm{T}$ lymphocytes (Goust et al., 1978; Knight et al., 1975). Further, it has been documented that MS patients may have an immunological response to white matter preceding a relapse (Myers and Ellison, 1975). In addition, immunosuppressive drugs including adrenocorticosteroids and ACTH have been reported to cause some improvement in treated patients (Cendrowski, 1975; Hommes et al., 1975; but see Millar et al., 1967).

There have been several studies of adrenocortical activity and of the behavior of the adrenocortexpituitary axis in MS patients (GarciaReyes et al., 1952; Teasdale et al., 1967; and Millac et al., 1969). Although the studies showed the MS patients to be normal in this respect, the studies were of an immediate and short-term nature. Approximately half of the patients in each of the studies were having a relapse; the other half were classified as stable. However, because the study was a one-time situation, no information could be provided relating changes of the disease status to the adrenocortical activity of the patients over an interval long enough to include several periods of stability and relapse for each of the patients.

In order to pursue the extendedterm nature of the problem, the present study was carried out over a period of one year with a group of patients, where some had relapses and others were stable. As the paper will show, it was found that people suffering relapses had levels of plasma 
cortisol that fluctuated more than those whose disease status was stable.

\section{MATERIALS \& METHODS}

The patients who participated in the study attended a regularly scheduled MS clinic at a large metropolitan hospital in the Detroit area. Only patients with clinically definite MS (Schumacher et al., 1965; Rose et al., 1976) were considered, as judged by one of the authors (G.E.R.). Control subjects, who were asymptomatic were either friends or relatives of the patients or were from the clinic staff. Only those patients (and control subjects) who visited the clinic three or more times throughout a one-year period were used for this report.

Clinical data were obtained from the patients' records and by direct examination by one of the authors (G.E.R.). MS has a variable course and, therefore, at any given time any patient will be in one of the four disease states. The states are: stable, where the patient shows no change from the previous clinical evaluation; progressive, where the patient's condition become slightly worse than in the previous visit; remission, where the symptoms and signs of the previous evaluation improve; and exacerbation, where the patient's condition becomes slightly worse than worse. Patients who showed a change in disease state (CDS) from the previous visit were classified as active. The period of time between visits averaged three months and ranged from three weeks to six months. Those who throughout the year remained the same neurologically were classified as stable. Control subjects had no known MS history. There were comparable distributions of ages and sexes in each of the three groups of individuals. Subjects did not receive adrenocorticosteroid or ACTH therapy while participating in the study.

During the clinic, blood was drawn from each subject participating in the study. Using Vacu-Tainers containing dry EDTA, blood was drawn during a one-hour interval (1:30-2:30 p.m.) and immediately stored on ice. About two hours later, plasma was prepared by centrifugation at $4^{\circ} \mathrm{C}$, aliquoted, quick-frozen in dry ice and ethanol, and stored in air-tight tubes at $-20^{\circ} \mathrm{C}$.

Cortisol levels were determined using the radioimmunoassay (RIA) method of Abraham et al. (1972) and Abraham (1975, personal communication). The cortisol antiserum was produced by Endocrine Sciences (Tarzana, California), ${ }^{3} \mathrm{H}$-cortisol (spec. act. $=40 \mathrm{Ci} / \mathrm{m} \mathrm{mol}$ ) was obtained from New England Nuclear Corporation and unlabeled cortisol was purchased from Steraloids, Incorporated (Wilton, New Hampshire). Tritiated cortisol was purified by chromatography on Sephadex LH20 (Pharmacia) just prior to use. The heat inactivation method was always employed on the plasma samples. A standard curve and plasmas containing known amounts of cortisol were used in each RIA run. In all RIA runs used, the coefficient of variation of the known plasmas was less than $10 \%$, and never greater than $10 \%$ of the expected value. Cortisol values were extrapolated and expressed as $\mathrm{ng} / \mathrm{ml}$ of plasma from a handdrawn standard curve and later verified by computation. The RIAs were done without any knowledge of the clinical results. Statistical comparisons of variations expressed as standard deviation of cortisol levels were carried out using Student's t-test and pooled estimate method.

\section{RESULTS \& DISCUSSION}

A one-year longitudinal study was carried out on MS patients in regard to their level of plasma cortisol and their disease course. The patients with clinically definite MS were assayed at least three separate times over a oneyear period for plasma cortisol levels. At the same time their disease course was ascertained by neurological exam. In addition, the plasma cortisol levels were determined in a group of control subjects who were asymptomatic. The results of this study are illustrated in Table 1.

There were three groups of subjects: Control, who were asymptomatic; MS-Stable, whose neurological condition remained constant for the year; and MS-Active, who experienced at least one relapse. Each group had comparable distributions of sexes and ages. There were about three times as many females as males in all these groups, and the age means and distributions were similar. Note that the distribution of ages in the control group was larger because the range was larger. The age at onset of the disease (AAO) was slightly higher in the MS-Active group (33 yrs as opposed to $29 \mathrm{yrs}$ ), which may be due to the fact that those patients in the MS-Active groups ( $E, G$, and $J$ ) have the same date of diagnosis as that of the AAO, suggesting that earlier symptoms went unnoticed. The duration of the disease had a similar mean and distribution for both MS groups. The average number of visits to the clinic were slightly greater for the MS patients than the control subjects.

In the final two columns on the far right of Table 1, the average cortisol level for the year and corresponding standard deviation for each patient are presented. The level of plasma cortisol, expressed in $\mathrm{ng} / \mathrm{ml}$, was determined for each patient's, visit to the clinic. The average of all of the visits is in column six of the table, and the corresponding standard deviation is in the seventh column. This standard deviation is the principal measure of cortisol fluctuation (CF) or variability in cortisol level and is, as will be shown below, related to the disease status of the patient.

The individual standard deviations or CF's (column 7, Table 1) were averaged for each of the three patient groups to produce a measure of the average cortisol fluctuation (ACF) of the patient group. When the ACF's of each of the groups were compared, statistically significant differences between certain groups were demonstrated. The ACF's of the control and MS-Stable groups are statistically the same when compared using Student's t-test $(P=0.7)$ and the pooled estimate method. However, when the ACF of the MS-Active is compared with that of the control or the MS-Stable group, the MS-Active average cortisol fluctuation is significantly greater at the 95 percent level than either of the other two groups, using Student's ttest or the pooled estimate test.

The significant difference between the MS-Active and the other two 
groups is due largely to the CF's of the patients who have experienced more than one relapse during the year. These patients are indicated with a " $V$ " (very active) in the first column of Table 1. The average cortisol fluctuation $(A C F)$ of the very active group is 76 (23). If this ACF is compared with that of the control or the MS-Stable groups, the differences are highly significant at the 99 percent level using either statistical test. The difference between the ACF's of the slightly active and very active groups is not significant $(P=0.15)$. However, if these ACF's are compared with those of the stable group, one sees a definite, increasing trend: stable, 42 (25); slightly active, 53(25); and very active, 76 (23). Although this trend is intriguing, more patient data is needed.

\section{TABLE 1}

Cortisol fuctuations in control, MS-Stable and MS-Active patients as depicted by the standard deviation (S.D.) derived from the average of cortisol determinations made over a one-year period.

\begin{tabular}{cc}
$\begin{array}{c}\text { PATIENT } \\
\text { GROUP }\end{array}$ & SEX \\
CONTROL & \\
A & F \\
B & F \\
C & M \\
D & F \\
E & F \\
F & F \\
G & M \\
H & M \\
I & F \\
J & F \\
\hline 10 &
\end{tabular}

$\begin{array}{lll}\text { AGE AT } & \text { NUMBER } \\ \text { AGE } & \text { ONSET } & \text { OF VISITS }\end{array}$

CORTISOL LEVEL FOR YEAR

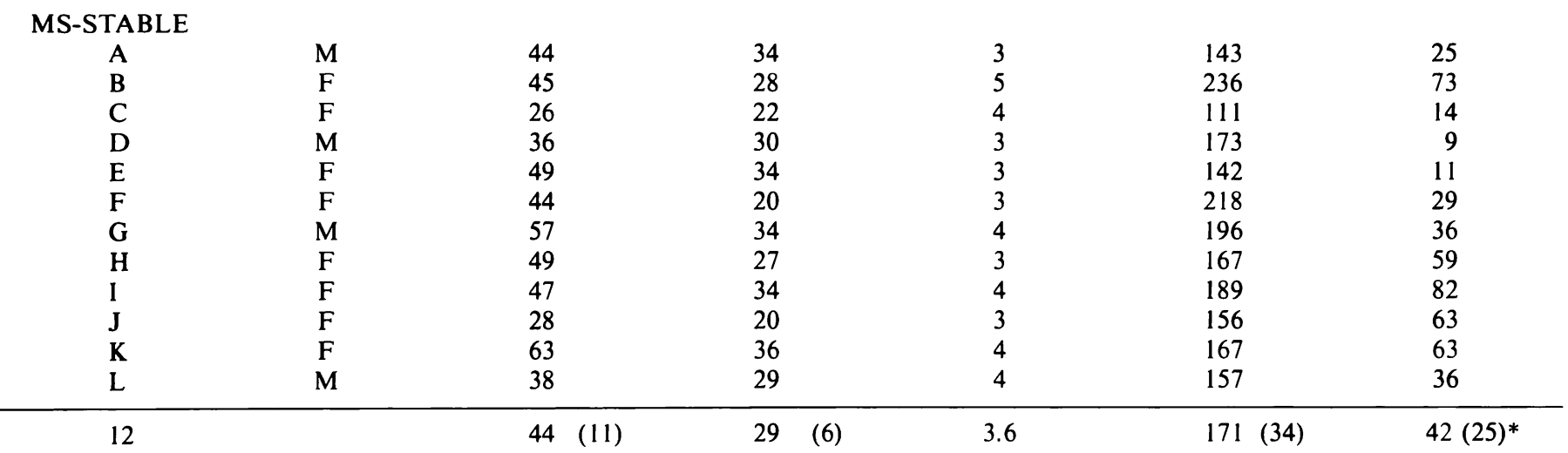

MS-ACTIVE

\begin{tabular}{|c|c|c|c|c|c|c|}
\hline A & $\mathrm{F}$ & 30 & 19 & 3 & 197 & 50 \\
\hline B & $\mathbf{M}$ & 51 & 37 & 3 & 120 & 25 \\
\hline $\mathrm{C}-\mathrm{V}^{* *}$ & $F$ & 48 & 19 & 3 & 294 & 113 \\
\hline D-V & M & 27 & 26 & 6 & 202 & 53 \\
\hline E-V & $F$ & 47 & 41 & 3 & 149 & 71 \\
\hline $\mathrm{F}-\mathrm{V}$ & $\mathrm{F}$ & 47 & 32 & 3 & 133 & 88 \\
\hline G & $\mathrm{F}$ & 59 & 49 & 4 & 110 & 41 \\
\hline $\mathrm{H}$ & $F$ & 40 & 29 & 3 & 131 & 56 \\
\hline $\mathrm{I}-\mathrm{V}$ & $\mathbf{M}$ & 45 & 32 & 4 & 123 & 78 \\
\hline$J-V$ & $\mathrm{~F}$ & 62 & 47 & 4 & 201 & 51 \\
\hline K & $\mathrm{F}$ & 54 & 29 & 3 & 182 & 93 \\
\hline 11 & & $46 \quad(11)$ & $33 \quad(10)$ & 3.6 & $167(55)$ & $65(26)^{*}$ \\
\hline
\end{tabular}

*Average cortisol fluctuation $(\mathrm{ACF})=$ average standard deviation of cortisol for each patient group. The number in parentheses is the corresponding standard deviation.

$* * \mathrm{~V}=$ very active $($ see text) 
An attempt was made to depict a causal relationship between the cortisol fluctuation and the active disease course. By graphing the cortisol levels and clinical evaluation for each visit for the active patients, one can see no obvious relationship exists. It must be borne in mind that in this graph the lines connecting the points are drawn solely for visual continuity. Although a relapse often difficult to ascertain from the records or the patient exactly when the relapse occurred. Of course, the cortisol levels during the interval were not known. Inspecting the graph, one can see some large cortisol fluctuations (CF) preceded the change in disease state (CDS); some CF occurred simultaneously with the occurred between two visits, it was

CDS, and other CF's followed the CDS. Clearly the intervals are large and a cause and effect analysis will have to await a study which includes more frequent clinic visits.

Although the difference in the magnitude of the fluctuations is statistically significant, the possibility that the MS-Active group's wide fluctuations are due simply to chance or other physiological parameters must be considered. It is known, for example, that the plasma cortisol levels of women fluctuate as a function of the monthly menstrual cycle. However, analysis of our data shows that although the females have greater average fluctuations than the men, the differences between the fluctuations in men and women of each of the groups
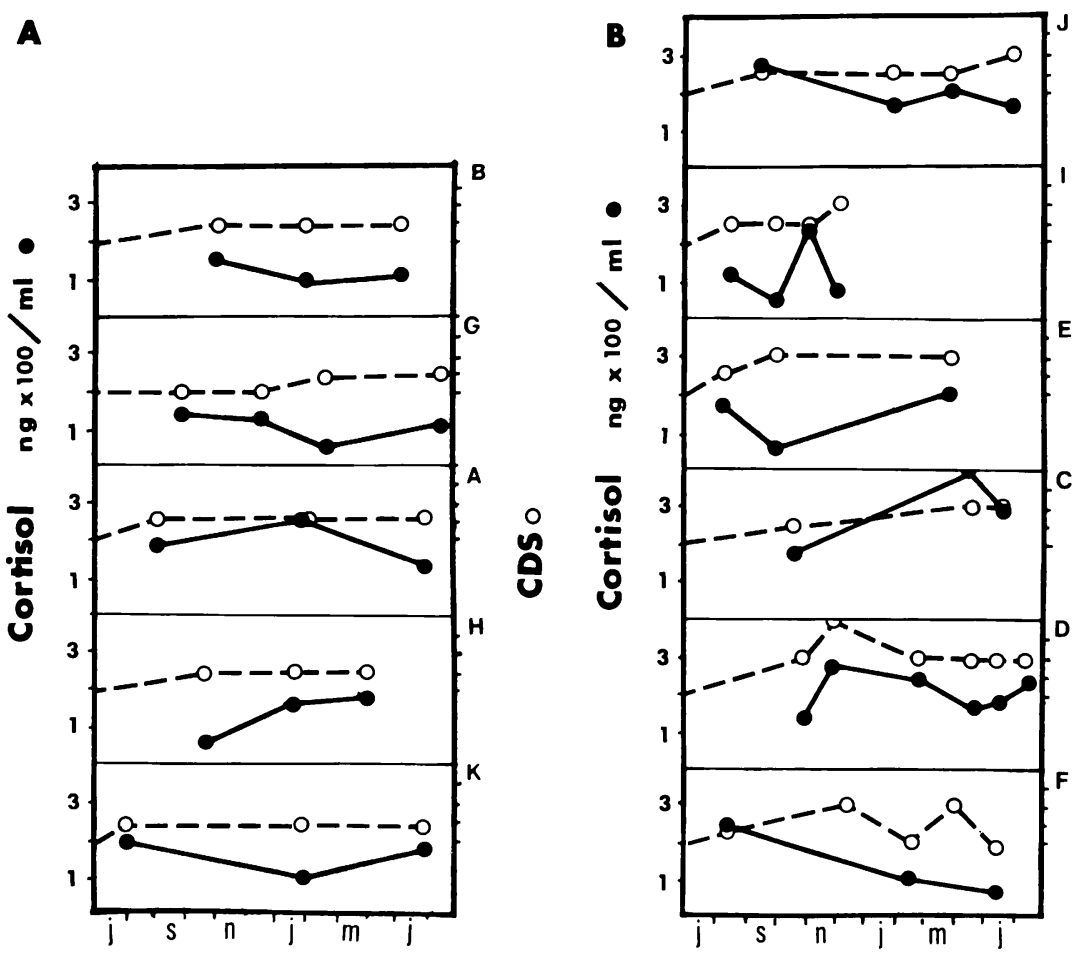

Figure 1 -Graphic representation of the cortisol levels $(\bullet-\bullet)$ and disease state (o----o) of the eleven MS-Active patients. The left-hand ordinate is plasma cortisol in $\mathrm{ng} / \mathrm{ml}$. The right-hand ordinate represents the disease status in arbitrarily-chosen units. When the line is parallel to the abscissa, the condition was stable. When the line rises one unit, the disease state was progressive since the previous visit. A two-unit rise depicts an exacerbation. A lowering of the line is a remission. The lines connecting points are for visualization purposes only. To the right of each curve are the patients' reference letters (see Table 1). The abscissa is time in months. Note that the patients in part A experienced only one progressive episode during the year. The patients in part B experienced at least two episodes. Also note that occasionally only the disease state of a patient was assessed, but the blood was not drawn. and also between those of men and women as a whole are not significant. Furthermore, a study of Abraham et al. (1972), where plasma cortisol was measured daily through a menstrual cycle, demonstrates the differences are small. Five values gave a standard deviation of less than $40 \mathrm{ng} / \mathrm{ml}$. Although the selected data were intentionally biased to inflate the standard deviation, the fluctuation is similar to that of the stable and control groups reported in this paper. In addition, Genazzini et al. (1975), using fluorometric analysis, also measured daily cortisol levels in 5 female subjects through 15 cycles. Again, a nonrandom averaging of 5 values of their data intentionally selected to yield the widest fluctuation gave an average standard deviation (ACF) of less than that found in our control or stable groups. Therefore, it is highly unlikely that variations due to changes in the menstrual cycle have had a significant effect on our results.

Elegant studies by Weitzman et al. (1971) have shown that the level of plasma cortisol varies cyclically throughout the course of a day. Blood samples collected every 20 minutes throughout 24 hours indicated the plasma cortisol levels of seven normal subjects reached peaks of nearly 200 $\mathrm{ng} / \mathrm{ml}$ early in the morning and moved downward to almost a zero level in the evening. During the downward movement, all individuals displayed episodic cortisol secretion. Although we chose to collect our samples at a fixed time in order to achieve optimal uniformity, there was a possibility that there were episodic secretions at the time the blood was drawn. However, analysis of the combined data of Weitzman et al. (1971) and Czeisler et al. (1976) shows that these episodic variations are relatively small and insignificant in terms of the magnitude of the fluctuations found. For example, we selected non-randomly to inflate the standard deviations 5 values per patient from their data (12 patients each with 10 samples taken from noon to 3 p.m.). Averaging the individual standard deviations yielded a variability that was smaller than that found in our control and MS-Stable groups. 
The Weitzman studies (1971) demonstrated two phases of cortisol secretory cycle: the major phase, in the early morning, which influenced the overall amplitude of the daily cycle, and the episodic phase, in the afternoon, which influenced the rate of cortisol decay. It is not known whether the same control mechanism regulates both phases. The large range of variability in the MS-Active patients may be due to variability in either of the two phases, because the plasma was collected during the middle of the episodic phase. In order to decide between the two alternatives, plasma would have to be collected earlier in the day. Secretion may not be the sole cause of the fluctuations, since the level of plalsma cortisol is due also to the rate of degradation.

The wide fluctuations of plasma cortisol in the MS-Active patients may be induced by the pathophysiological effects of the disease. But perhaps the variability is due to effects secondarily related to the disease. For example, the fluctuations may be induced by changes in daily routines peculiar to one suffering a relapse (for example, see Weitzman, 1975); induced by depression (Sachar, 1975); or perhaps simply the MS-Active patient may be more susceptible to the psychological stress of venapuncture itself (Czeisler et al., 1976). On the other hand, there is a possibility that a defect exists in the hypothalamus-pituitary-adrenal-cortex (HPAC) axis in the MS-Active subjects. Studies of Garcia-Reyes et al. (1952), Teasdale et al. (1967), and Millac et al. (1969) have shown that the HPAC axis performs normally in MS-Active patients in response to specific pharmacological stimuli. However, because of the short-term nature of these studies, one cannot rule out the possibility of sporadic malfunctions in the HPAC axis in active patients over extended periods of time.

In conclusion, the results of a longitudinal study of MS patients showed that patients having an active disease course over a one-year period had plasma cortisol levels that fluctuated significantly more than patients whose disease course was stable and also asymptomatic control subjects. The data suggest that the more active the disease course, the more widely fluctuating the plasma cortisol levels.

\section{ACKNOWLEDGMENT}

The generous financial support of Abilities Unlimited, Southfield, Michigan, and Oakland University is gratefully acknowledged. The authors also with to extend their thanks to staff of the Grace Central Hospital MS Clinic, particularly Nurses S. Lawther, K. Poe, and B. Wingaard. Gratitude is also extended to Drs. $\mathrm{H}$. Arnold and S. Perla for their useful discussions concerning statistical matters; to Dr. G. E. Abraham for instructing us in RIA; and to Drs. G. Ellison, L. Myers, A. Roy, and V. Moudgil for their encouragement and reading the manuscript. Appreciation is given to $\mathrm{Mr}$. K. Thompson for his technical help; to Mrs. E Motycka of the MS Society, Michigan Chapter, for her assistance; and to the patients who volunteered for the project.

\section{REFERENCES}

ABRAHAM, G. E., BUSTER, J. E., and TELLER, R. C. (1972): Radioimmunoassay of plasma cortisol. Annalyt. Letters 5, 757765.

CENDROWSKI, W. S. (1975): Pilot-study on large dose alternate-day therapy in multiple sclerosis. Schw. Arch. f. Neurol. Neuroch. u. Psych. 117, 197-203.

CZEISLER, C. A., EDE, M. C. M, REGESTEIN, Q. R., KISCH, E. S., FANG, V.S., and EHRLICH, E. N. (1976): Episodic 24-hour cortisol secretory patterns in patients awaiting cardiac surgery. J. clin. Endocrinol. Metab. 42, 273-283.

GARCIA-REYES, J. A., JENKINS, D. FORSHAM, P. H., and THORN, G. W. (1952): Adrenocortical function in multiple sclerosis. AMA Arch. Neurol. Psychiat. 62, 776-782.

GENAZZINI, A. R., LEMARCHANDBERAUD, T., AUBERT, M. L., and FELBER, J. P. (1975): Pattern of plasma ACTH, hGH, and cortisol during menstrual cycle. J. clin. Endocrinol. Metab. 41, 431437.

GOUST, J. M., CHENAIS, F., CARNES, J. E., HAMES, C. G., FUNDENBERG, H. H., and HOGAN, E. L., (1978): Abnormal T cell subpopulations and circulating immune complexes in the Guillain-Barre syndrome and multiple sclerosis. Neurology 28, 42I425.

HOMMES, O. R., PRICK, J. J. G., and LAMMERS K. J. B. (1975): Treatment of the chronic progressive form of multiple sclerosis with a combination of cyclophosphamide and prednisone. Clin. Neurol. Neurosurg. 78, 59-72.

KNIGHT, S. C., LANCE, E. M., ABBOSH, J., MONRO, A., and O'BRIEN, J. (1975): Intensive immunosuppression in patients with disseminated sclerosis. III. Lymphocyte response in vitro. Clin. exp. Immunol. 21, 23-31.
MYERS, L. W., and ELLISON, G. W. (1975): Longitudinal study of the immune response to normal human white matter in multiple sclerosis. Neurology 25, 351.

MILLAC, P., COOK, D. B., and CHASE, K. (1969): Endocrine function in multiple sclerosis, J. Neurol. Neurosurg. Psychiat. 32, 414-418.

MILLAR, J. H. D., VAS, C. J., NORONKA, M. J., LIVERSEDGE, L. A., and RAWSON, M. D. (1967): Long-term treatment of multiple sclerosis with corticotrophin. Lancet 1, 429-431.

ROSE, A. S., ELLISON, G. W., MYERS, L. W. and TOURTELLOTTE, W. W. (1976): Criteria for the clinical diagnosis of multiple sclerosis. Neurology 26, 20-22.

SACHAR, E. J. (1975): Twenty-four-hour cortisol secretory patterns in depressed and manic patients. Prog. Brain Res. 42, 81-91.

SCHUMACHER, G. A., BEEBE, G., KIBLER, R. F., KURLAND, L. T., KURTZKE, J. F., McDOWELL, F., NAGLER, B., SIBLEY, W. A., TOURTELLOTTE, W. W., and WILLMON, T. L. (1965): Problems of experimental trials of therapy in multiple sclerosis: Report by the panel on the evaluation of experimental trials of therapy in multiple sclerosis. N.Y. Acad. Sci. Ann. $122,552-568$.

TEASDALE, G. M., SMITH, P. A., WILKINSON, R., LATNER, A. L., and MILLER, H. (1967): Endocrine activity in multiple sclerosis. Lancet 1, 64-68.

WEITZMAN, E. D. (1975): Neuroendocrine pattern of secretion during the sleep-wake cycle of man. Prog. Brain Res. 42, 93-102.

WEITZMAN, E. D., FUKUSHIMA, D., NOGEIRE, C., ROFFWARG, H., GALLAGHER, T. F., and HELLMAN, L. (1971): Twenty-four-hour pattern of the episodic secretion of cortisol in normal subjects. J. clin. Endocrinol. Metab. 33, 14 22.

SCHUMACHER, G. A., BEEBE, G.. KIBLER, R. F., KURLAND, L. T., KURTZKE, J. F., McDOWELL, F., NAGLER, B., SIBLEY, W. A., TOURTELLOTTE, W. W., and WILLMON. T. L. (1965): Problems of experimental trials of therapy in multiple sclerosis: Report by the panel on the evaluation of experimental trials of therapy in multiple sclerosis. N.Y. Acad. Sci. Ann. $122,552-568$

TEASDALE, G. M., SMITH, P. A., WILKINSON, R., LATNER, A. L., and MILLER, H. (1967): Endocrine activity in multiple sclerosis. Lancet 1, 64-68.

WEITZMAN, E. D. (1975): Neuroendocrine pattern of secretion during the sleep-wake cycle of man. Prog. Brain Res. 42, 93-102.

WEITZMAN, E. D., FUKUSHIMA, D., NOGEIRE, C.. ROFFWARG, H., GALLAGHER, T. F., and HELLMAN, L. (1971): Twenty-four-hour pattern of the episodic secretion of cortisol in normal subjects. J. clin. Endocrinol. Metab. 33, 14-22. 


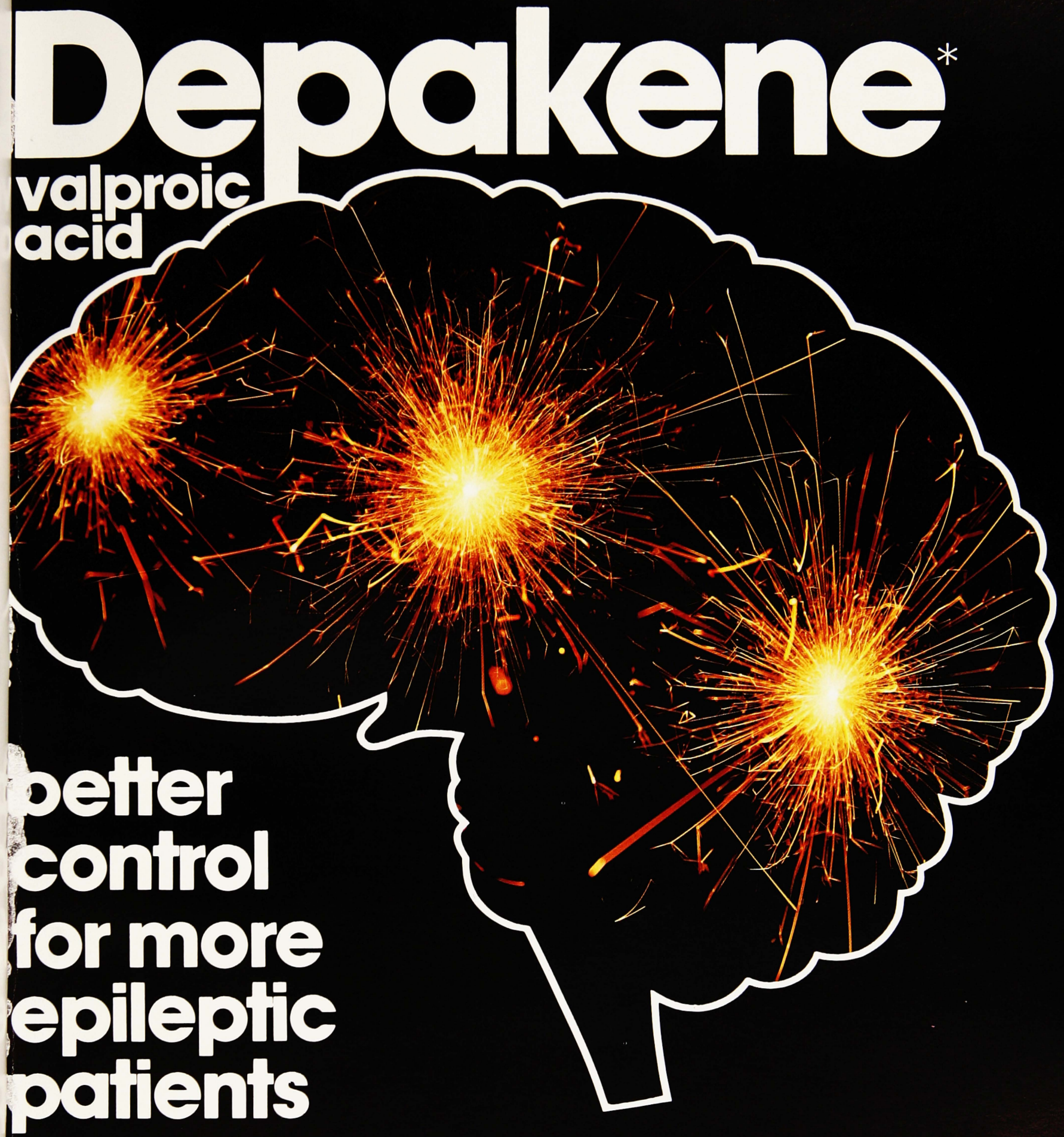




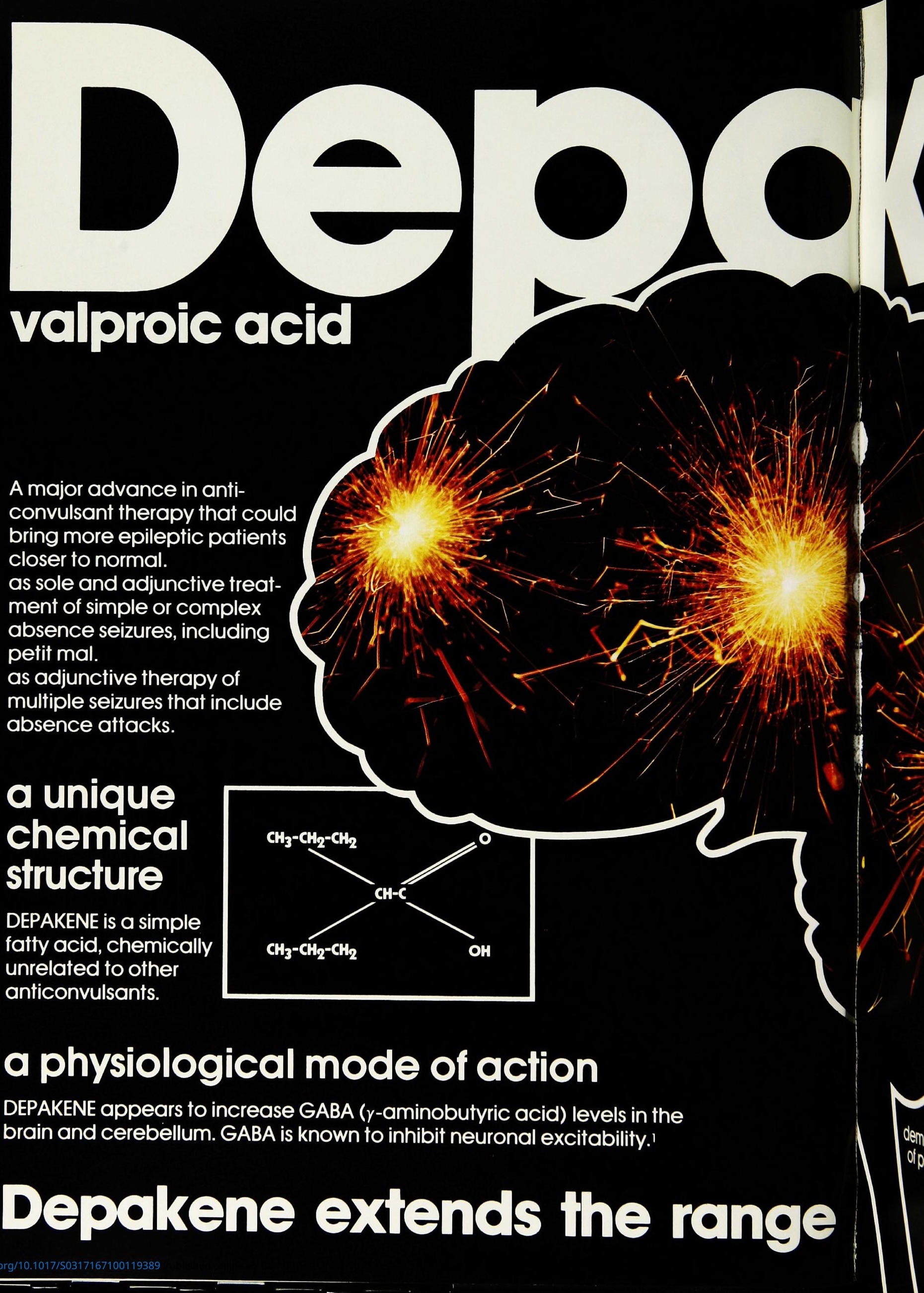




\section{Prescribing Information}

CLINICAL PHARMACOLOGY

Depakene (valproic acid) has anticonvulsant properties. Although its mechanism of action has not yet been established, it has been suggested that its activity is related to increased brain levels of gammaaminobutyric acid (GABA)

Valproic acid is rapidly absorbed after oral 作 列 life (to.5) of valproic acid is approximately 8 to 12 hours. Valproic acid is rapidly distributed throughout the body and the drug is strongly bound $(90 \%)$ to human plasma proteins. The therapeutic plasma concentration range is believed to be from 43 to $86 \mu \mathrm{g} / \mathrm{mL}$.

Excretion of valproic acid and its metabolites occurs principally in the urine, with minor amounts in the feces and expired air. Very liftle unmetabolized parent drug is excreted in the urine. The principal metabolite formed in the liver is the glucuronide conjugate.

\section{INDICATIONS AND CLINICAL USE}

Depakene (valproic acid) is indicated for use as sole and adjunctive therapy in the treatment of simple and complex absence seizures, including petit mal. Valproic acid may also be used adjunctively in patients with multiple seizure types which include absence.

In accordance with the International Classification of Seizures, simple absence is defined as a very brie clouding of the sensorium or loss of consciousness (lasting usually 2-15 seconds), accompanied by certain generalized epileptic discharges without other detectable clinical signs. Complex absence is the term used when other signs are also present

\section{CONTRAINDICATIONS}

Depakene (valproic acid) is contraindicated in patients with known hypersensitivity to the drug.

\section{WARNINGS}

Liver dysfunction, including hepatic failure resulting in atalities, has occurred in a few patients receiving Depakene (valproic acid) and concomitant anticonvulsant drugs. These events have occurred during the first six mo cauld be should be observen when adminstering Depakene to tests should be performed prior to therapy and every two months thereatter.

\section{Use in pregnancy}

The safety of Depakene (valproic acid) during pregnancy has not been established, however, animal studies have demonstrated teratogenicity. Therefore, the physician should weigh the potential benefits agains the possible risks in treating or counselling women of childbearing age who have epilepsy.

Recent reports indicate an association between the use of anticonvulsant drugs and an elevaled incidence of bith defiction ching regarded to be approximately $2 \%$; in children of treated epictic women this incidence may be increased two to threefold. The increase is largely due to specific defects, e.g. congenital malformations of the heart, and defects, e.g. congenital malformations of the heart, and of mothers receiving anticonvulsant medications deliver normal infants.

Data are more extensive with respect to

diphenylhydantoin and phenobarbltal, but these drugs are also the most commonly prescribed anticon vulsants. Some reports indicate a possible similar assoclation with the use of other anticonvulsant drugs, including trimethadione and paramethadione. However, the possibility also exists that other factors, e.g genetic predisposition or the epileptic condition itself may contribute to or may be mainly responsible for the higher incidence of birth defects.

Anticonvulsant drugs should not be discontinued in patients in whom the drug is administered to prevent majo seizures, because of the strong possibility of precipitating status epilepticus with attendant hypoxia and risk to both the mother and the unborn child. With regard to drugs given for minor seizures, the risks of discontinuing medication prior to or during pregnancy should be weighed against the risk of congenital defects in the particular case and with the particular family history.

Epileptic women of chlld-bearing age should be encouraged to seek the counsel of their physician and should report the onset of pregnancy promptly to him medication is in doubt, appropriate consultation might medication is
be indicated.

\section{Nursing Mothers}

Depakene is secreted in breast milk. As a general rule, nursing should not be undertaken while a patlent is receiving Depakene.

Fertility

Chronic toxicity studies in juvenile and adult rats and dogs demonstrated reduced spermatogenesis and testicular atrophy at doses greater than 350 $\mathrm{mg} / \mathrm{kg} / \mathrm{day}$ in rats and $90 \mathrm{mg} / \mathrm{kg} / \mathrm{day}$ in dogs. The efof the testis and on sperm production and fertility in of the testis and on spe
humans is unknown.

PRECAUTIONS

General

Because of rare reports of platelet aggregation dysfunction, thrombocytopenia and elevated liver enzymes, it is recommended that liver functlon tests, platelet counts and bleeding time determinations be performed before initiation of therapy and at periodic intervals.

Because valproic acid may interact with other anticonvulsant drugs, periodic serum level determinations of such other anticonvulsants are recommended during the early part of therapy (see Drug Interactions) Valproic acid is partially eliminated in the urine as a ketone-containing metabolite which may lead to a false interpretation of the urine ketone test.

\section{Driving and Hazardous Occupations}

Valproic acid may produce CNS depression, especially when combined with another CNS depressant, such as alcohol. Therefore, patients should be advised not to engage in hazardous occupations, such as driving a car or operating dangerous machinery, until it is known that they do not become drowsy from the drug.

\section{Drug Interactions}

Depakene (valproic acid) may potentlate the CNS depressant action of alcohol.

There is evidence that valproic acid may cause an increase in serum phenobarbital levels, although the mechanism is unknown. Patlents receiving concomitant barbiturate therapy should be closely monifored for neurological toxIclity. Serum barblturate drug levels should be obtained, if possible, and the barbiturate dosage decreased, if indicated.

There is conflicting evidence regarding the inter action of valproic acid with phenytoin. it is no known if there is a change in unbound (ire $\theta$ ) phenytoin serum levels. The dose of phenytoin sifuation.

The concomitant use of valproic acid and clonazepam may produce absence status. Caution is recommended when valproic acld is administered with drugs affecting coagulation, $\Theta . g$. acetylsalicyll acid and warfarin (see Adverse Reactions)

\section{ADVERSE REACTIONS}

The most commonly reported adverse reactions are nausea, vomlting and indigestion. Since Depakene (valproic acid) convulsants, It is not possible in most cases to determine whether the adverse reactions mentioned in this section are due to valproic acid alone or to the combination of drugs.

Gastrolntestinal

Nausea, vomiting and indigestion are the most commonly reported side effects at the initiation of therapy. These effects are usually transient and rarely require discontinuation of therapy. Diarrhea, abdominal cramps and constipation have also been reported. Anorexia with some weight loss and increased appetite with some weight gain have also been seen.

\section{CNS Effects}

Sedative effects have been noted in patients recelving valproic acid alone but are found most often in patients on combination therapy. Sedation usually disappears upon reduction of other anticonvulsant medication. Ataxia, headache, nystagmus, diplopia, asterixis, "spots coordination have rarely been noted. Rare cases of coma have been reported in patients who were also on phenobarbital

Dermatologic

Transient increases in hair loss have been observed Skin rash and petechiae have rarely been noted.

Psychiatric

Emotional upset, depression psychosis, aggression hyperactivity and behavioural deterioration have been reported.

Musculoskeleial

Weakness has been reported.

Hematopoletic

Valproic acid inhibits the secondary phase of platelet aggregation. This may be reflected in altered bleeding time. Relative lymphocytosis and mild thrombocytopenia have also been noted in isolated cases. Leukopenia has been reported.

Hepatic

Increases in serum alkaline phosphatase and serum glutamic oxaloacetic transaminase have been noted glutamic oxaloacetic transaminase have been noted reported (se日 Warnings).

SYMPTOMS AND TREATMENT OF OVERDOSAGE

In a reported case of overdosage with Depakene (valproic acid) after ingesting $36 \mathrm{~g}$ in combination with phenobarbital and phenytoin the patient presented in deep coma. An EEG recorded diffuse slowing compotible with the state of consciousness. The patient made an uneventful recovery.

As valproic acld is absorbed very rapidly, gastric lovage may be of limited value. General supportive measures should be applied with particular attention to the prevention of hypovolemia and the maintenance of adequate urinary output.

DOSAGE AND ADMINISTRATION

Depakene (valprolc acid) is administered orally. The recommended initial dose is $15 \mathrm{mg} / \mathrm{kg} /$ day, increasing at one week intervals by 5 to $10 \mathrm{mg} / \mathrm{kg} / \mathrm{day}$ until seizures are controlled or side effects preclude further increases. The maximum recommended dose is $30 \mathrm{mg} / \mathrm{kg} /$ day. When the total daily dose exceeds $250 \mathrm{mg}$, it is given in a divided regimen
Weight

kg 24.9

25-39.9

$40-59.9$

75-89.9

22-54.9

$22-54.9$
$55-87.9$

$88-131.9$

$165-197.9$

As the dosage of valprolc acld ls raised, blood levels of phenobarbifal and/or phenytoin may be affected (see

Patlents who experlence G.I. Irrltation may benefil from administration of the drug with food or by a progresslve increase of the dose from an inlilal low level. The capsules should be swallowed without chewing to avoid local irrltation of the mouth and throat.

1. Roberts. E.: Formation and utilization of gammaaminobutyric acid in brain. In: S.R. Korey \& J.I. Nurnberge (Eds.), Progress in Neurobjology. it Neurochemlstry. 2. Simon, D., Penry, K.J.: Sodium Di- $\underline{N}$-Propylacetate (DPA)
Table of Initial Doses by Weigh

$$
\begin{gathered}
\text { Total Dally } \\
\text { Dose (mg) } \\
250 \\
500 \\
750 \\
1,000 \\
1,250
\end{gathered}
$$

\section{AVAILABILITY}

Depakene (valproic acld) is avallable as orangecoloured, soft-gelatin capsules of $250 \mathrm{mg}$ in bottles of $10 \mathrm{O}$ and as a red syrup containing the equivalent of $250 \mathrm{mg}$ valproic acid, as the sodlum salt. per $5 \mathrm{~mL}$ in bottles of $450 \mathrm{~mL}$. Depakene is a prescription drug (ScheduleF).

in the Treatment of Epllepsy. Epilepsig 16.549-573. 1975 3. Pinder, R.M. et al., Sodium valproate: Aं Review of its Pharmacological Propertles and Therapeutic Efficacy in Epilepsy. Drugs 13, 81-123. 1977. 